\title{
BC reinstates one of seven fired PharmaNet employees
}

$\mathrm{N}$ early two years after the British Columbia Ministry of Health launched an investigation that resulted in the firing of seven scientists and officials with access to drug records in the provincial PharmaNet databases, it has reinstated one of them.

Robert Hart, whose employment as director of Data Access and Research Stewardship was terminated Aug. 31, 2012, "has been fully reinstated to his employment with the provincial government," says Hart's lawyer, Robert Gill.

Although Gill said he is "unable to respond" to questions regarding the ministry's explanation for its apparent about-face, or whether it has paid compensation to Hart, he confirmed that Hart would "to the best of my understanding" be granted the same level of data access and responsibility as he held before his termination.

The PharmaNet databases are North America's most comprehensive source of population-wide drug safety and efficacy data, drawn from all pharmacists, patients and clinicians throughout BC.

"Mr. Hart relies on the fact of full reinstatement as a demonstration of the government's continuing confidence in him, as a loyal and dedicated public servant with over 29 years service," Gill added in an email.

BC Ministry of Health spokesman Ryan Jabs said the ministry "will not comment on personnel matters out of respect for the privacy and confidentiality of the individual involved. However, we can confirm we've recently rehired an individual who previously worked with the Ministry of Health."

"It looks like the BC government is starting to admit they massively overreacted," says Alan Cassels, a University of Victoria pharmaceutical researcher. "They're starting to undo the damage."

Hart was terminated during an investigation that former health minister Margaret MacDiarmid said involved alleged potential conflicts of interest, contracting and inappropriate data management. In September 2012, Mac-

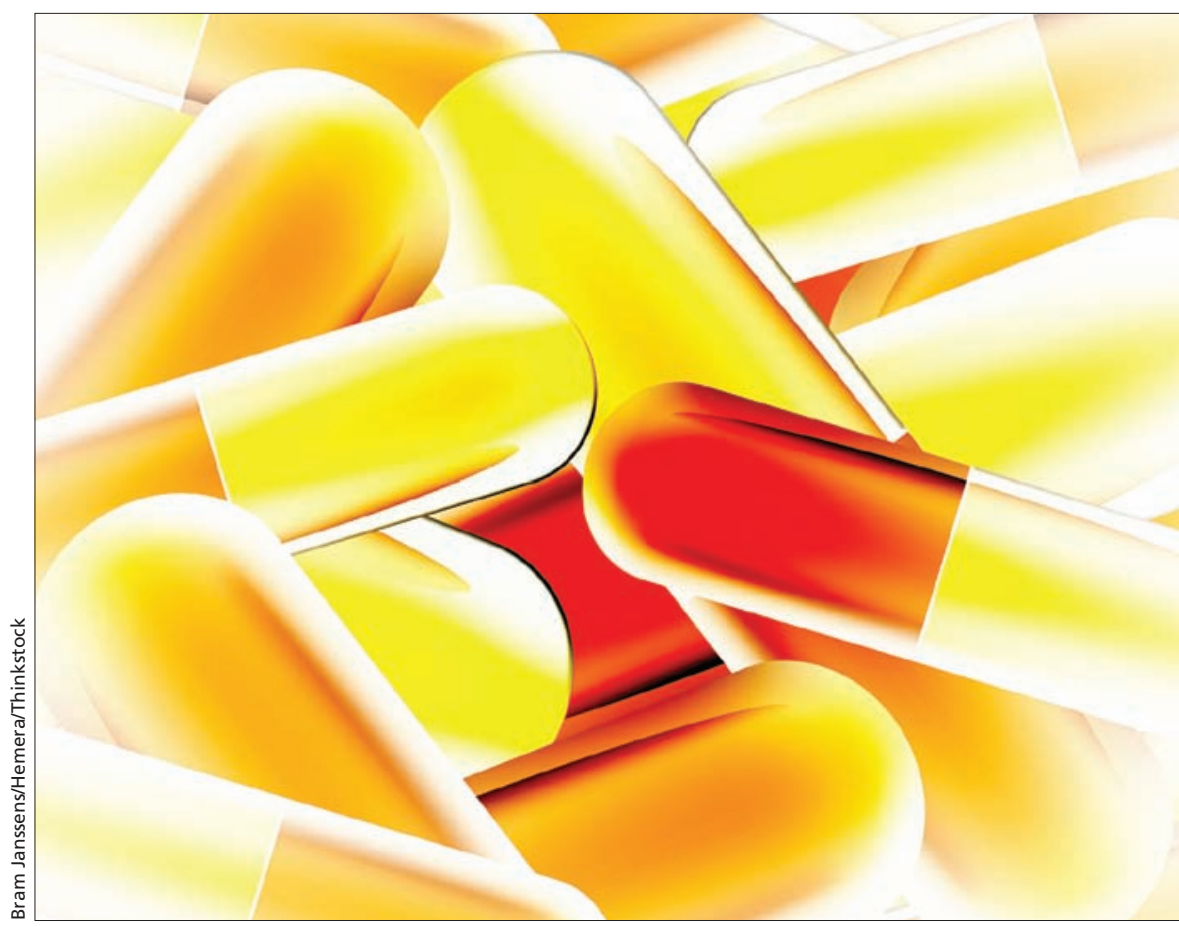

British Columbia's PharmaNet databases are the most comprehensive source of population-wide drug safety and efficacy data in North America.

Diarmid said the Royal Canadian Mounted Police (RCMP) had been called in to investigate. In a subsequent lawsuit against the government, Hart said he was fired without just cause or notice and then repeatedly defamed by the government in press releases.

Ron Mattson, who once worked with Hart managing drug data and studies, was terminated under similar circumstances and filed a similar lawsuit. But Mattson's lawyer, Chris Siver, says the government has not offered to settle with his client. "Trying to discern anything that may be applicable to Mr. Mattson's case is next to impossible" he added. "As we have stated from the beginning, we remain hopeful the government will do the right thing and we are willing to assist them in doing so."

Three ministry officials who were also fired went through a labour grievance process but were not reinstated. One of them, Roderick MacIsaac, committed suicide in January 2013.
Three scientists associated with the University of British Columbia and the University of Victoria were also terminated. All have filed lawsuits against the government. All of them say their suits have yet to be resolved. The most senior among them, Malcolm Maclure, who holds the BC Academic Chair in Patient Safety, has described the charges against him as "vague" and says the news of his firing struck him as "difficult to believe."

MacDiarmid lost her seat in the May 2013, provincial election, and has been replaced as minister. Graham Whitmarsh, the deputy minister who approved the terminations, was shuffled from his job after the election.

"I would say it appears the new deputy minister and his team are doing their best to work through a very difficult situation," says Lawrie McFarlane, a former BC deputy minister of health. - Paul Christopher Webster, Toronto, Ont.

CMAJ 2014. DOI:10.1503/cmaj.109-4758 